\title{
Kana-Kanji Conversion System with Input Support Based on Prediction
}

\author{
Yumi ICHIMURA, Yoshimi SAITO, Kazuhiro KIMURA and Hideki HIRAKAWA
}

\author{
Human Interface Isaboratory \\ Corporate Research \& Development Center, TOSHIBA Corp. \\ 1, Komukai-Toshiba-cho, Saiwai-ku, Kawasaki-shi, \\ Kanagawa, 212-8582 Japan \\ yumi.ichimura@toshiba.co.jp
}

\begin{abstract}
We propose a kana-kanjiconversion system with input support based on prediction. This system is composed of two prarts: prediction of strcceding kanji character strings from typed kana ones, and ordinary kana-kanji conversion. It, automatically shows candidaties of kanji char-acter strings which the user intends to input. Our prediction method features: (i) Arbitiary positions of typed kana character strings are regarded as the top of words. (ii) $\Lambda$ system dictionary and a user dictionary are used, and each cutry in the system dictionary has certainty factor calculated from the frequency of words in corpora. (iii)Candidates are estimated by cerlainty factor and usefulness factor, and likely ones with greater factors than thresholds are shown. The proposed system could reduce the user's key input operations to $78 \%$ from the original ones in our experiments.
\end{abstract}

\section{Introduction}

TOSHIB $\Lambda$ developed the world's first Japanese word processor in 1978. Unlike langrages based on an alphabet, Japanese uses thousands of lanji characters of varying complexity. Hence, to arrange all of kanji characters on keyboard is difficult. On the other hand, kana characters which are phonetic seripts of Japanese have 83 variations; these can be arranged on keyboard. As a result, conversion from kana notations to kanji ones, what is called lana-kanji conversion, has been used. Since Japanese is not written separately by words, segmentation of typed kana character strings has ambiguity. And an ambiguity in conversion exists, too; a kana notation may correspond to some different; kanji notations. These make kana-kanji conversion challenging.

We have made efforts to raise a precision of kana-kanji conversion, thinking that high precision can provide a better input environment for the user. $\Lambda$ precision of our kana-kanji conversion system reaches $95-98 \%$ for several kinds of texts in our previous experiments. Nevertheless, this approach is not enough in the situations where fast typing is hard, e.g., for beginners who are not familiar with keyboard or for palm-size computers. Thus, new method to reduce key inputi operations is needed.

We propose a kana-kanji conversion system with input support based on prediction. This system is composed of two parts: prediction of succeding kanji character strings from typed kana ones, and ordinary kana-kanji conversion. It automatically shows candidates of kanji character strings which the user intends to input. The candidates change as the user inputis kane characters. If no appropriate choice is presented, the candidates automatically disappeas when the next kana character is entered. Our system, therefore, can be used in the same manner as an ordinary lana-kanji conversion system, and allows the user to save time and efforts for key input, without learning new key operations.

We have been considered two issues to generate accurate candidates:

(i) How to determine where typed kana character strings are segmented; since Japanese is not written separately by words, determination of positions where words start is needed to retrieve dictionaries.

(ii) How to determine when prediction candiclates are presented; if all of retrieval results are always shown, a system cannot be convenient.

Surveying previous works from the view on above issues, we found that the Reactive Keyboard has been proposed (Darragh et al., 1980). It accelerates typewritten communication with 
a computer system by predicting what the uscr is going to type next. In this system, the top of typed character strings is regarded as the top of words, because English is written separately by words; the issue of segmentation of character strings does not occur.

On the other hand, in previous works for Japanese, a predictive pen-based text input method has becn proposed (Fukushima and Yamada, 1.996). In this system, character strings are input by hand-writing on ICD panel. Since the user usually inputs not only by kane but also by kanji and an alphabet, cntered character strings are segmented with the help of the variety of characters. Thus, the issue of segmentation is not considercd.

The POBox (Pen-Operations Based On cXample) which is a text input method for penbased computers has also been proposed (Masui, 1998). It shows succecding candidates from character strings input by software keyboard. Arbitrary positions of input character strings can be regarded as the top of words, and retricval results are always shown as candidates; the prediction ordering is based on the user's previous choice. Since input speed by pen is not faster than that by keyboard, time to choose candidates is shorter than that to input characters. Hence, even if many candidates are shown, this method is effective for pen-based computcr's. It is, however, inefficient for ordinary keyboard.

We propose a system with following features:

(i) Arbitrary positions of typed kana character strings are regarded as the top of words.

(ii) A system dictionary and a user dictionary are used, and each entry in the system dictionary has certainty factor calculated from the frequency of words in corpora.

(iii) Candidates are cstimated by certainty factor and usefulness factor, and likely ones with greater factors than thresholds are shown.

These features provide an efficient Japanese text input environment for ordinary keyboard without learning ncw key operations.

Section 2 shows an cxample of text input using the proposed system. Section 3 explains an input support method based on prediction. Section 4 shows cfficiency of our systcm by means of experiments. Section 5 describes conclusions.

\section{Example of Text Input}

Figure 1 shows an example of text input using the proposed systcm. Suppose that the user intends to input a sentence “下記の会漾を開位し ますのでご桨粙願います (we request your attendance at the following mecting)", typing kana charactcrs “かきのかいぎをかいさいしますのでご さんしゅう称がいます (kakino kaigiwo kaisai shimasunode gosanshuu negaimasu)". When the

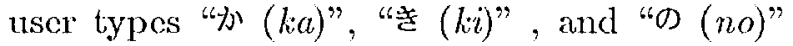
keys, the system automatically opens a prediction menu window just below the typed characters, and shows two candidates in the menu window (Fig.1(a)):

下記の住所にささやかながら

(at the following address, modest ... )

下記の住刚にささやかな

(at the following address, modest ...)

The first candidate is highlighted. If the menu window contains an appropriatc candidate, the user can choose it by cursor; otherwise the user can continue entering the next characters. Subsequently, when "js (ka)" key is typed, the prediction menu window disappears (Fig.1(b)). When "W (i)" and "ぎ (gi)" keys are typed, the system automatically opens a prediction menu window again, and shows four now candidates (Fig.1(c)):

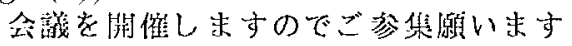

(we request your atiendance at the meeting)

会請を鬥唯します

(we hold the mecting)

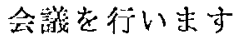

(we hold the mecting)

会䛢を鞢り行いま寸

(we hold the mecting)

Here the first one is what the user just wants; the user enters select key, then the prediction menu window disappears, and chosen candidate is inserted in the edit area. If remaining kana character string which was not included in the chosen candidate exists, kana-kanji conversion starts automatically; the first thrce kana characters of this sentence “かきの (kakino)" is converted to kanji notation "下記の (the following)" (Fig.1(d)). This is the first result of kana-kanji conversion, so that the user can change it to others. An overline of the conversion result in Fig.1(d) shows that this result is not fixed yet.

In above example, while 27 kana characters are needed to input in ordinary kana-kanji con- 
(a)

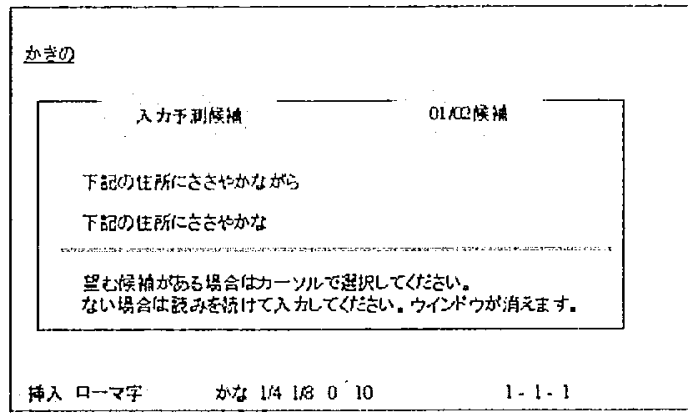

(b)

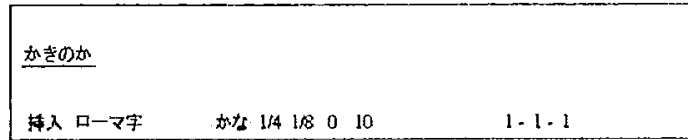

(c)

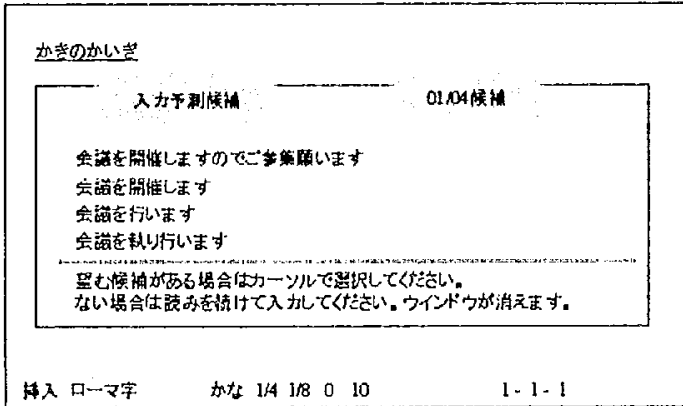

(d)

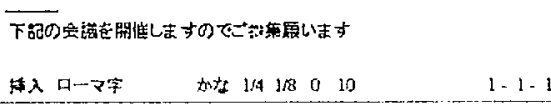
1. 1 -

F'igure 1: Example of Japanese texi input using word processor with input support. (a)“か”, “き”, and "の" keys are typed. (b) "か" liey is typed, subsequently. (c) "い" and "き" keys are typed, subsequently. (d)The first candidate in (c) is chosen.

version, our systcm can reduce the input of 21 kana characters, “をかいさいしますのでごさんしゅ う好がいます (wo kaisai shimasunode gosanshuu negaimasu)"; only 6 kana characters are needed to input.

\section{Input Support Method Based on Prediction}

In this section, an overview of the system is shown. Then dictionaries used in the system, factors for estimation of candidates, and user learning are described.

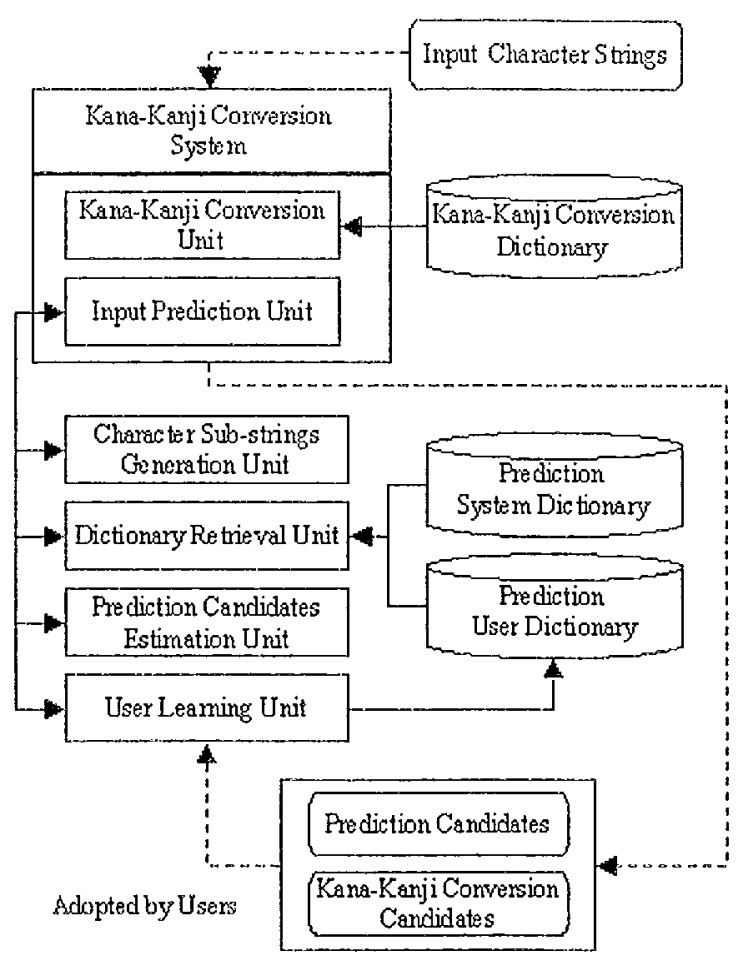

Figure 2: Diagram of the proposed system.

\subsection{Overview of the system}

Figure 2 shows a diagram of the proposed system. It is composed of a kana-kanji conversion unit and an input prediction unit, and the latter has following four sub-units:

Character Sub-strings Generation Unit(a) generates character sub-strings obtained from segmentation of typed kana character strings.

Dictionary Retrieval Unit(b) retrieves prediction dictionaries using character sub-strings generated by Unit(a).

Prediction Candidates Estimation Unit.(c) calculates certainty factor and usefulness factor for all of retrieved results by Unit(b) to estimate candidates.

User Learning Unit(d) extracts phrases adopted by the user, and automatically registers them into the user dictionary.

\subsection{Prediction Dictionary}

Two kinds of dictionaries are used as a predic-tion source:

(i) System Dictionary consists of high frequent phrases. 
(ii) User Dictionary consists of phrases learned from texts which the user typed before.

Each dictionary includes words and phrases without distinction. This is because Japanese is not written separately by words, and high frequent phrases consist of various grammatical forms, such as single word or two words. And cach entry has kana notation (phonetic seript) and kanjione.

\subsection{Estimation of Prediction Candidates}

Two kinds of factors are used to estimate candidates:

(i) Certainty Factor indicates how certain a candidate is.

(ii) Usefulness Factor indicates how useful a candidate is.

These two factors vary as the user inputs a character. Retricval results are sorted in order of these factors, and only ones with greater factors than thresholds are shown as candidates.

\subsection{Calculation of Certainty Factor}

Certainty factors for cntries in the system dictionary and the user dictionary are calculated in different manner.

First we make some notational conventions. $\Lambda$ typed kana character string is denoted by $S$, which has right, sub-strings $S_{i}(1 \leq i \leq L(S))$. $L(x)$ is the length of a string $x$. An entry in the dictionary is denoted by $W$, which has kanji notation $W_{H}$ and lana notation $W_{\mathrm{Y}}$.

\subsubsection{Entry of System Dictionary}

When $S$ is typed, certainty factor for $W$ in the system dictionary is calculated as follows:

\section{Certainty factor $(W \mid S)=$}

$\left\{\begin{array}{cl}F_{H}\left(W_{H}\right), & \text { when } S \text { has a right sub-string } S_{i} \\ F_{K}\left(S_{i}\right) & \text { which partially matches with the } \\ & \begin{array}{l}\text { head of } W_{Y} \\ 0,\end{array} \\ \text { otherwise }\end{array}\right.$

where $F_{H}\left(W_{H}\right)$ is the frequency of $W_{H}$ in kanji notation corpus, and $F_{K}\left(S_{i}\right)$ is the frequency of $S_{i}$ in kana notation corpus corresponding to kanji one.

For example, certainty factor for “小 小漠学变 掺 (kana-kanji conversion)" is calculated using the frequency in Table 1:
Table 1: Frequency for “小な漠字変换” in two corresponding corpora: kanji notation corpus with 155,000 characters, and lana one with 227,000 characters.

$\begin{array}{lc}\text { Character strings } & \begin{array}{c}\text { Frequency in } \\ \text { kana notalion corpus }\end{array} \\ \text { か } & 6,720 \\ \text { かな } & 191 \\ \text { かなか } & 114 \\ \text { かなかん } & 94 \\ \text { かなかんじ } & 87 \\ \text { かなかんじへ } & 78 \\ \text { かなかんじへん } & 77 \\ \text { かなかんじへんか } & 76 \\ \text { かなかんじへんかん } & 76\end{array}$

Frequency in kanii notation corpus 加港学変換
70

$$
\begin{aligned}
& \text { Certainty factor(か深字変抁｜かな) } \\
& =70 / 191=0.366
\end{aligned}
$$

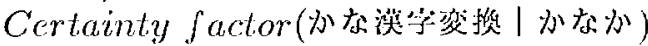

$$
\begin{aligned}
& =70 / 114=0.614
\end{aligned}
$$

The values of certainty factor corresponding to every character sub-strings are described in the system dictionary, and are read out at: retricval.

\subsubsection{Entry of User Dictionary}

Since the system cannot infer which phrases would be registered into the user dictionary, calculation of certainty factor for an entry in the user dictionary from corpora may be impossible. Hence, when $S$ is typed, cerlainty factor for $W$ in the user dictionary is calculated as follows:

$$
\text { Certainty factor }(W \mid S)=
$$

$$
\left\{\begin{array}{cl}
N\left(S_{i}\right), & \text { when } S \text { has a right sub-string } S_{i} \\
& \text { which partially matches with the } \\
& \text { head of } W_{Y} \\
0, & \text { otherwise }
\end{array}\right.
$$

where $N\left(S_{i}\right)$ is the number of entries whose kana notations start from $S_{i}$ in the user dictionary, and $\alpha$ is a constant to give greater factor for entries in the user dietionary than that in the system dietionary; i.e., the user dictionary has priority. 


\subsection{Calculation of Usefultuess Factor}

$\Lambda \mathrm{n}$ increase in the length of typed hana charracter strings raises the certainty on prediction, but lessens the usefulness. Hence, usefulness factor is introduced in addition to certainty factor. When $S$ is typed, uscfulness factor for $W$ is calculated as follows:

$$
\begin{aligned}
& \text { Usefulness factor }(W \mid S)= \\
& \left\{\begin{array}{cl}
L\left(W_{Y}\right)-L\left(S_{i}\right), & \text { when } S \text { has a right stib- } \\
& \text { string } S_{i} \text { which partially } \\
& \text { matches with the head } \\
& \text { of } W_{Y} \\
0, & \text { otherwise }
\end{array}\right.
\end{aligned}
$$

\subsection{User Learning}

After the user adopts prediction or kana-kanji conversion candidates, words with longer length than threshold and phrases which satisfy given grammatical conditions are extracted; these are automatically registered into the uscr dictionary.

For example, suppose that the user intends

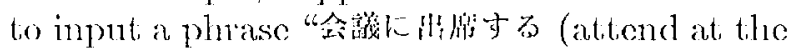
meet.ing)", typing kana characters “かいざにし

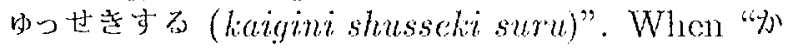

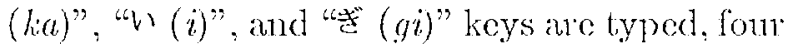
candidates are shown in the prediction mentu window (Fig.1(c)). Here the prediction menu window dose not contain a candidate which the uscr wants, then the user continues entering the noxt kana characters “にしゅっぜきする (ni shussehi suru)" and kana-kanji conversion key. $\Lambda$ s a result, "かいぎにしゅっせきする（Kaigini

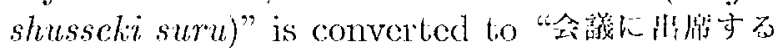
(atitend at the meeting)".

When this conversion candidate is adopted, two words and a phrase are registered into the

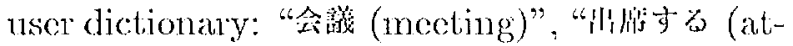

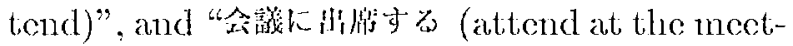
ing)". If “が (kal)", “い (i)", and “ぎ (gi)" keys

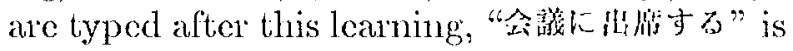
contained in the prediction menu window.

\section{Experiments}

Efficiency of the proposed system is shown by means of experiments.

\subsection{Evaluation Measures}

Neither start key for prediction nor cancel key for prediction candidates are needed. And se- lect key to adopt candidates is needed in both of prediction and ordinary kana-kanji conversion; we need not take into account of the inputi of select key. Hence, the length of complemented kana characters is just a decrease in key input. opcrations. Two cvaluation measures, an operation ratio and a precision, are defined as follows:

$$
\begin{gathered}
\text { Operation ratio }=\frac{P-Q}{P} \times 100(\%) \\
\text { Precision }={ }_{S}^{R} \times 100(\%)
\end{gathered}
$$

where $P$ is the length of the original kana text, $Q$ is the length of kana characters complemented by prediction, $R$ is the number of shown prediction ment1 windows containing appropriate choices, and $S$ is the number of all of shown prediction menu windows.

\subsection{Data and Conditions}

Two kind of texts, a paper on natural language processing and a letter, were used in our experiments; these texts were not included in the corpora used to calculatie certainty factor. $\Lambda$ system dictionary with 37,926 entrics was used. Thresholds of certainty factor and usefulness fartor were 0.1 and 2 . The number of candidates presentied in a prediction mentu window was five or less. If a prediction menu window contained an appropriate choice, it, was always adopted. With a view to examining cach contribution of the system dictionary and user learning, experiments were carricd out in three cases:

(i) Only the system dictionary was used.

(ii) Only user learning was used.

(iii) Both the system dictionary and user lcarning were used.

We calculated the length of complemented liane characters automatically. $\Lambda \mathrm{n}$ operation ratio and a precision were recorded at every input of 4,500 kana characters.

\subsection{Resultis}

Figure 3 shows experimental results.

Decrease in key input operations: Using both the system dictionary and user lcarning, for the par per, an operation ratio was $97.3-78.6 \%$ (line (13) in Fig.3(a)) and a precision was 20.0-26.7\% (line (p3) in Fig.3(c)); for the letter, an operation ratio was $80.7-78.1 \%$ (line (13) in Fig. $3(b)$ ) and a precision was $26.129 .6 \%$ (line (p3) in 


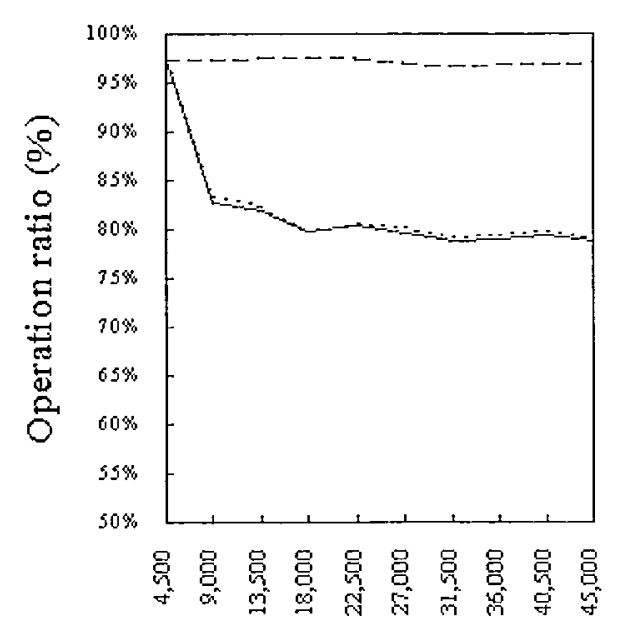

(a) Paper : the number of input characters

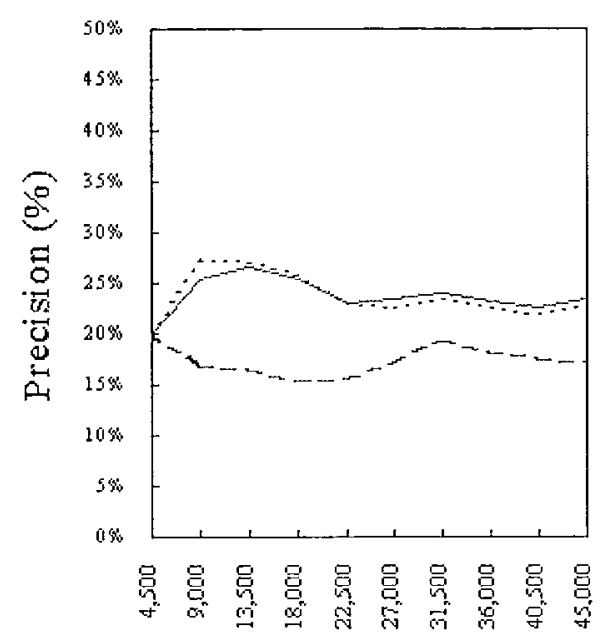

(c) Paper : the number of input characters
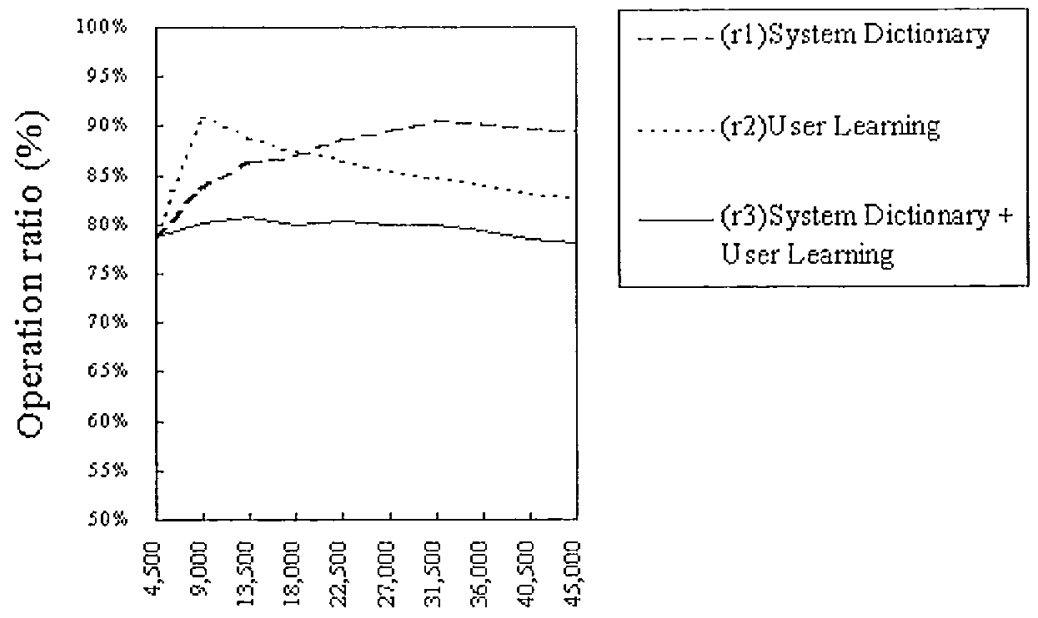

(b) Letter: the number of input cliracters
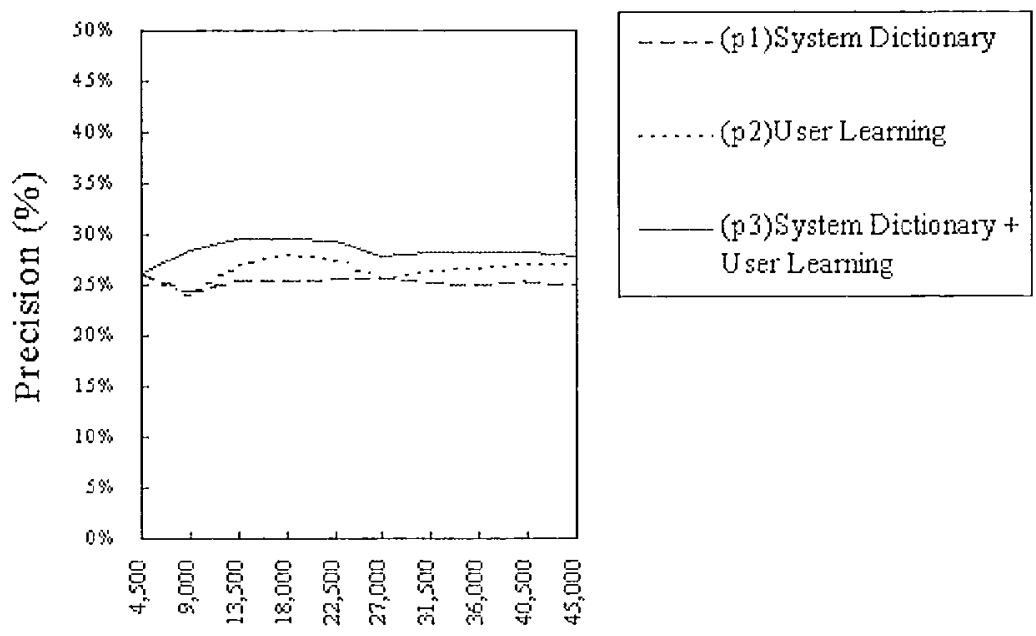

(d) Letter : the number of input characters

Figure 3: Experimental Results. (a) Operation ratio for the paper. (b)Operation ratio for the letter. (c) Precision for the paper. (d)Precision for the letter.

Fig.3(d)). When 45,000 kana characters werc typed, an average of the operation ratio was $78 \%$, that is, a $22 \%$ decrease in the original opcrations was obtained; an average of the precision was $25 \%$, that is, a quarter of shown prediction menu windows contained appropriate choices. This precision was enough to rcalizc comfortable opcrations.
Contribution of the system dictionary: Using only the system dictionary, for the paper, an operation ratio was $97.6-96.6 \%$ (line (r1) in Fig.3(a)), that is, a $2.4-3.4 \%$ decrease in the original operations was obtained; for the letter, an operation ratio was $90.6-78.8 \%$ (line (r.1) in Fig. $3(\mathrm{~b})$ ), that is, a $9.4-21.2 \%$ decrease in the original opcrations was obtained. As a result, the system dictionary is effective for a text like a letter with idioms or common phrases, because 
the system dictionary includes a lot of such phrases. Furthermore, compared a precision using both the systicm dictionary and user learning with that using only user learning, the former was worse for the paper (lines (p2) and (p3) in Fig.3(c)(d)). $\Lambda$ s a result, for some kind of texts, the system dictionary not only is ineffective but also reduces a precision.

Contribution of user learning: User learning had an effect for an opcration ratio after more than 9,000 kana characters were typed (lines (12) in Fig.(a)(b)). In fact, if the user typos about ten pages of texts, a $15-20 \%$ decrease in the original operations can be obtained.

\section{Conclusions}

We proposed a kana-kanji conversion systom with input support based on prediction. Our systiem featiures:

(i) It shows prediction candidates of hanji chanacter strings which the reser intends to input without any special key operation. If no appropriate choice is presented, the candidates disappear automatically when the next kana character is entered.

(ii) Mrbitiary positions of typed hana character strings are reganded as the top of words.

(iii) $\Lambda$ system dictionary and a nsen dictionary are used, and each entry in the system dictiomary has cerlatinty factor calculated from the frequency of words in corpora.

(iv) Candidates are estimated by certainly factor and usefulness factor, and likely ones with greater factors than thresholds are shown.

(v) Words and phrases are extracted from typed texts, and registiered into the user dictionary antomatically.

The proposed system could reduce the user's key input operations to $78 \%$ from the original ones in the experiments using two kinds of texts. This system was built into the TOSHIB $\Lambda$ Japanese word processor, the $J W-8020$, which was relcased in autumn 1.998 (Fig.4).

To raise a precision by field information and context of textis is our future work.

\section{References}

Alice Carlberger, Johan Carlberger, Tina Magnuson, Sira E. Palazuclos-Cagigas, M. Sharon Hunnicutt, and Santiago Aguilera Navarro. 1997.

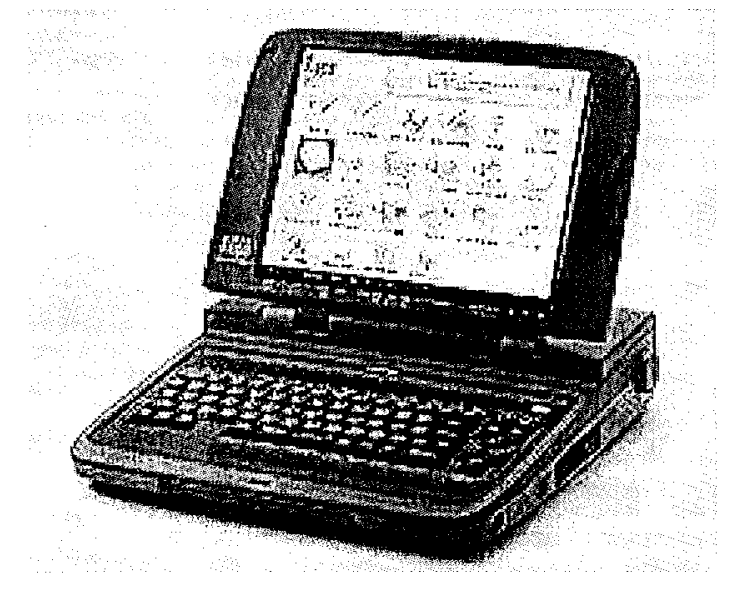

Figure 4: TOSHIBA Japanese word processor, the $J W-8020$, where the proposed system was built.

Profet, a new genenation of word prediction: $A$ n craluation study. In Proceedings of the $A C T$, Worhishop on Natural Ianguage Processing for Communication Aids, pages 23-28, July.

Joln J. Darragh, Tan H.Witten, and Mark T. James. 1980. The reactive keyboard: A predictive typing aid. IEEE Compuler; 23(11):41-49, November.

Toshikazu Fukushima and Hiroshi Yamada. 1996. A predictive pen-based japanese text input method and its craluation (in japanese). Journal of Information Processing Socicly of Japan, 37(1):23 30 .

Xestor Garay-Vitoria and Julio G. Mbascal. 1997. Word prediction for inflected languages. applicartion to basque languagc. In Procedings of the ACT Workshop on Nalural Language Processing for Communicalion Aids, pages 29-35, July.

Toshiyuli Masui. 1998. An efficient text input method for pen-based computers. In Proceedings of the $A C M$ Conference on Human Factors in Compuling Syslems (CHI'98), pages 328-335. Addison-Weslcy, April.

Masakat.su Sugimoto. 1997. Input scheme for japanese text with shk leycard (in japanese). In IPSJ STGMBT, Report No.1, pages 1-6, May. 